ISSN - 23214406

\title{
SOCIO- DEMOGRAPHIC DATA AND EXTENT OF UTIILIZATION ANTENATAL CARE SERVICES AMONG WOMEN IN COMMUNITIES IN ABI LOCAL GOVERNMENT AREA, CROSS RIVER STATE NIGERIA
}

EZE AJI

Department of Health Information Management Ndem, Major,Nigeria. Email: ezeaji@yahoo.com

Received: 04 Nov 2019, Revised and Accepted: 19 Dec 2019

\begin{abstract}
Socio-Demographic Data is a sensitive indicator used nationally and internationally to measure and compare the health and development status of the population. Access to care and early neonatal death rate are associated in maternal health around the time of delivery. Therefore, clinical antenatal care service before labor are important tool to identify the gaps/strength in this regards. The study was carried out to examine the extent of antenatalcare service utilization by women in riverine communities of Abi Local Government Area of Cross River State. To achieve the objective of the study three (3) research question were formulated and tested at .05 alpha level of significance. A random sampling of 800 wom en of reproductive age were selected from seven (7) communities in Abi Local Government Area of Cross River State formed the sample of the study. The data collected were analyzed using mean scores and independent t- test analysis for the research question raised. The result of the findings from research question 1 revealed that healthcare provider's attitude influences the attitude of antenatal services by women. In research question 2 the findings indicated that location of health facilities affect utilization of antenatal care. Findings from research 3 revealed that maternal religion influence the utilization of Antenatal care services. Findings from hypothesis 4 revealed thatmarital status significantly influence the utilization of antenatal care by women. Above all, the study recommended among others that Government should update it's official guidelines for antenatal care according to new standard promoted by World Health Organization. Also, improved transport and telecommunication facilities at health centers where such care is provided should be enhanced to strengthen accessibility of antenatal care.
\end{abstract}

Keywords: Socio-Demographic Data,Extent of Antenatal Care Services ,Utilization, Women In cross River State.

\section{INTRODUCTION}

In Nigeria, as in most developing countries, women of reproductive age (WRA) constitute more than one- fifth of the total population According to World Health Organization(2006) Women Reproductive Age are exposed repeatedly to the risk of pregnancy, continuous child bearing and the attendant morbidity mortality. They opined that the bad condition is exacerbated under existing socio-economic conditions and the inadequacy ion of medical and health facilities.

Women of Reproductive age often face serious health risk during pregnancy either for themselves or children. In Africa, especially the sub-saharan region, pregnancy related health risks caused about a quarter of burden of disease in 1990 for women in the age group of 15 to 44 years (Gupta, 2007). Despite steady decline over the past decade, maternal mortality ratio of about 1000 deaths per 100,000 live births (WHO, 2001). Within Africa, Nigeria ranks quite high with a maternal mortality ratio of 585 per 100,00 (WHO, 2005).

However, Alakija (2000) indicated that the situation had improved in the past decade. It was 11 over 1000 live births a decade ago. Yet, even with such level, it is still high when compared to other African countries like sudan and Ghana with 3 to 5 deaths per 1000 live births as at 2002 not to mention, the less than per deaths per 100,000 life births for the developed countries.

UNICEF, (2015) a woman's chance of dying from pregnancy and child birth in Nigeria is 1 in 13 and that 145 women of child bearing age die every single day to pregnancy related causes. This makes the country the second contributors to maternal mortality rate in the world and the worst in Africa

Antenatal care is that health care given to a pregnant woman and to the developing fetus until the time of delivery. Gupta (2007) Stated that health of a pregnant woman has been found to be significantly influenced by the utilization of antenatal care. This is because antenatal care can help to identify those women who are at risk of complications during pregnancy and delivers, and thus, ensuring that they obtain special attention in suitably equipped facilities. It also provides an invaluable opportunity to increase the awareness of women, their families and communities of the risk of pregnancy and how this can be overcome. The extent of utilization of modern antenatal clinic and the increase in proportion of mothers who visit trained personnel for antenatal checkup, therefore indicates the success being made in improving maternal health.

Expectant mothers who obtain sufficient antenatal care generally have better pregnancy outcome than those who lacks such Care, both in terms of their own health condition and that of their babies. Antenatal care whose sole aim is the care of the expectant mother from time of conception to delivery and six weeks postpartum is taken very seriously in the developed world. This is to enhance the chance of healthy babies being delivered to healthy uninjured mothers. In most parts of the developing world like Nigerian and most sub -saharan Africa the provision of Antenatal care services is yet to gain full recognition most especially in the rural communities (WHO, 20017).

Utilization of antenatal services enables general medical supervision of the expectant mother under the care or supervision of a medical personnel. From the earliest stages. It enables the physician or midwife to start treatment on time (Park, 2002).

\section{RESEARCH QUESTIONS}

They study will seek answer to the following questions:

Doeshealthcare providers attitude influences the utilization of antenatal care by women?

Does location of healthcare facilities influence the utilization of antenatal care by women?

Does religion influences the utilization of antenatal care by women in the communities?

What is the influence of maternal martial status on the utilization of antenatal care by women in the communities?

\section{METHODOLOGY}

This chapter presents the method and procedure used by the researcher in assessing the extent of utilization of antenatal care by women in Abi Local Government Area of Cross River State. The 
presentation is done under the following sub- headings; research design, area of the study, population for the study, sample and sampling techniques. Others are, instrument for data collection, and the method for data analysis.

\section{RESEARCH DESIGN}

A descriptive cross sectional design was used for this study, this design is considered most appropriate as it allows the researcher to collect first hand primary information from large population of respondent in their natural settings for the purpose of giving it detailed descriptions. Simiarly, Osuala (2001) stated that the method involves collection of data based on questionnaire and it also helps the researcher to identify, study and analyze occurrences and conditions as they exists.

\section{SAMPLE AND SAMPLING TECHNIQUE}

A sample size of 800 was drawn for the study from 7 villages in the Local Government Area of Abi using simple random sampling techniques. In each of the communities, purposive sampling is a deliberately non-randomized method of sampling to sample a group in a particular characteristics.

Table 1: Available healthcare facilities in the 7 villages in Abi Local Government Area of Cross River State

\begin{tabular}{ll}
\multicolumn{2}{c}{ Local Government Area of Cross River State } \\
\hline Villages in L.G.A & Number \\
\hline Itigidi & 2 \\
Ekwereku & 2 \\
Adadama & 1 \\
Usumutong & 1 \\
Igoni Goni & 1 \\
Ediba & 2 \\
Ebom & 1 \\
TOTAL & 10 \\
\hline
\end{tabular}

\section{INSTRUMENT FOR DATA COLLECTION}

The researcher developed instrument socio -Demographic variables and extent of women utilization of antenatal care. Questionnaire was used as the instrument to elicit information for the study. It is consisted of five section A,B,C,D,E, Section A was to elicit information on Demographic information of the respondents. Section B elicited information on the utilization of antenatal care services. The items $(B$, C\&D) were scored using "agreed = 2points" or disagreed 1 point" for positive question and the reverses for negative question. The face and content of the instrument was submitted as a pool of items, which was first submitted to an experts who went through it and made necessary corrections. Face validity refers to the appropriateness of measures in terms of general appearance, while content validity is the extent to which items in the instrument are related to the sample of the universe of content, be it cognitive or effective. The face and content validity was later established by three experts in education and department of foundations of faculty of education, in University of Calabar, Calabar. An instrument validation questionnaire was developed to assist the experts on the validation of the instrument was produced based on items accepted by two or more of the experts.

The reliability of the instrument was established by using a pilot group that were not part of the main study but, were found to the equivalent in all respect bearing age in riverine community of Etigeve in Abi, Cross River State using split -half method. Reliability index indicated the consistency of the instrument with reliability coefficient of 0.87 indicating a high level of reliability.

\section{METHOD OF DATA ANALYSIS}

Mean, standard deviation, and independent t-test were used in data analysis.

\section{RESULT AND DISCUSSION}

This chapter focused on the analysis of the research data using the descriptive statistics. The results of the analysis of date are presented below.

Table 1: Summary of independent t-test analysis of health provider's attitude and utilization of antenatal health services $(\mathrm{n}=\mathbf{8 0 0})$

\begin{tabular}{lcccc}
\hline ATTITUDE & $\mathrm{N}$ & Mean & SD & t-cal \\
\hline Positive & 526 & 13.15 & 2.04 & 6.27 \\
negative & 274 & 13.05 & 1.91 & \\
\hline
\end{tabular}

*Significant at 0.05 level of significant

Result from the analysis above revealed that health providers attitude significantly influence utilization of health services by women.

Table 2: Summary of independent t-test analysis of location and utilization of health care services

\begin{tabular}{ccccc}
\hline Location & $\mathrm{N}$ & Mean & SD & t- cal \\
\hline Close & 311 & 13.24 & 1.93 & 6.45 \\
Far & 489 & 13.04 & 2.03 & \\
\hline
\end{tabular}

*Significant at 0.05 level of significance

The result from the table 10 shows that location significantly affectthe utilization of antenatal health services by women.

Table 3:Mean and standard deviation on utilization of Antenatal

\begin{tabular}{llll}
\multicolumn{3}{c}{ care by religion } \\
\hline Religion & $\mathbf{N}$ & Mean & SD \\
\hline Traditional Religion & 38 & 13.22 & 1.99 \\
Christian & 760 & 13.11 & 2 \\
Moslem & 2 & 13 & 0 \\
Total & $\mathbf{8 0 0}$ & $\mathbf{1 3 , 1 2}$ & $\mathbf{2 , 0 0}$ \\
\hline
\end{tabular}

Table 4: Mean and standard deviation on utilization of antenatal

\begin{tabular}{|c|c|c|c|}
\hline Marital status & $\mathbf{N}$ & Mean & SD \\
\hline Married & 399 & 13.43 & 2.07 \\
\hline Separated/divorce/widow & 102 & 12.85 & 1.92 \\
\hline Single & 299 & 12.8 & 1.87 \\
\hline Total & 800 & 13,12 & 2,00 \\
\hline
\end{tabular}

As shown in table 5, the mean square scores 13.43 of married women on the utilization of antenatal care greater than that of the widows 12.85: while the mean score 12.85 of the widows were greater than that of student 12.80 .

\section{DISCUSSION OF FINDINGS}

Findings from research question 1 reveal that Healthcare providers attitude influence the utilization of antenatal services. The attitude of the health care providers will either promote or limit the utilization of antenatal services. Good attitude will motivate the women to attend while poor attitude will limit utilization of antenatal services and will result to high rate of maternal mortality within the community (Gupta, 2007).

Research question 2 shows that the location of health facilities affect utilization of antenatal services. WHO (1991) stated that the availability of health facilities influenced the rate of women attending the services. Those who have knowledge will attend no matter the location while the illiterate ones will hinder the rate of attendances

Research question 3 indicated that maternal religion influence the utilization of antenatal care. Adamu (2002) supported that religious belief influenced the attendance of antenatal services and this often lead to abstructed labor and complication such as pre- eclampsia.

Research question 4 indicate that marital status influence the utilization of antenatal care. Addai (1998) affirmed that mothers that are married has less problem of attending antenatal services and has a safer condition of health than women that are married, have problem of money and stay off from antenatal services.

\section{CONCLUSION}

Based on the findings, it was concluded that, Healthcare provider attitude, location, religion and education significantly influenced the utilization of antenatal services by women in the communities. Hence, Government collaboration with health agencies should embark on information campaign so that women of child bearing age can be made more aware of the importance of sufficient antenatal care for their health and that of the new born child. 


\section{RECOMMENDATIONS}

Based on the finding of the study, the following recommendationswere made

Government should encourage all child bearing women to enroll in adult education program in order to improve their educational status by provision of evening classes to suit the mothers and also the government should enforce its educational policy to provide all children with at least nine years basic education which might improve the future antenatal care utilization.

Government should embark on information campaign so that women of child bearing age can be made more aware of importance of sufficient antenatal care for their health and that of their new born children

\section{REFERENCE}

1. Gupta, P. (2007) Preventive and Social Medicine $4^{\text {th }}$ edition. CBS Publication, London

2. Park, K. (2002) Preventive and Social Medicine. Banasida Banhot Press India.
3. Ajala A.S. (2003). Integrating Traditional And Western Medicine in Healthcare System in Nigeria. In P.A Doganu Et Al (Eds.) African Culture. Modern Science and Religious Thought Horin: African Center For Religion And Science.

4. Alakija, W. (2000) Maternal and Child Health Care And Family Planning: Essentials of Community Health Primary Healthcare and Health Management. Benin City Soectrum Book ltd.

5. Alam, A. Quereshi., A Adil, M, \& Ali (2004). Factor Affecting Utilization of Antenatal Care Among Women in Urban Slum Area of Islamabed. Rawal Medical Journal, 29, 71-75.

6. Adamu, Y. M \& Salihu, H.M (2002). Barriers to the Use of Antenatal and Obstetric Care Services in Rural Kano. Journal of Obstetrics and Gynecology, 22, (6), 600-603

7. Achalu O. E \& Achalu E. I (2004) The Concept of Health Promotion and Lifestyle. Nigeria School Health Journal, 16, (2), 25-32.

8. Abanobi O.C \& Ewuzie M.A (2000) Health and illness: A Behavioural Approach. Owerrri: Mantle Publishers Nigeria. 